\begin{tabular}{|c|c|}
\hline $\begin{array}{c}\text { European Association for the } \\
\text { Development of Renewable Energies, Environment } \\
\text { and Power Quality (EA4EPQ) }\end{array}$ & $\begin{array}{c}\text { International Conference on Renewable Energies and Power Quality } \\
\text { (ICREPQ'12) }\end{array}$ \\
Santiago de Compostela (Spain), 28th to 30th March, 2012
\end{tabular}

\title{
Hybrid solution for photovoltaic and photothermal conversion
}

\author{
K. Znajdek and M. Sibiński \\ Department of Semiconductor and Optoelectronic Devices, \\ Technical University of Lodz \\ 211/216 Wolczanska, 90-924 Lodz (Poland) \\ phone number: +4842 6312681, fax number: +48426368024 , \\ e-mail: katarzyna.znajdek@p.lodz.pl, maciej.sibinski@p.lodz.pl
}

\begin{abstract}
In this paper an idea and a realization of a hybrid solution for photovoltaic and photothermal conversion is presented. Proposed solar hybrid system integrates photovoltaic (PV) module and solar thermal collector in one device, which provides direct conversion of solar energy into electricity and heat simultaneously.

Origins of the idea and proposal of the solution are presented. Performance and operation of both integrated system and stand alone devices have been measured and analyzed. Obtained results show the advantage of synergy for combined thermo electrical appliance. Future development and possible industrial applications are proposed.
\end{abstract}

\section{Key words}

Renewable energy, photovoltaic conversion, photothermal conversion, solar hybrid device.

\section{Introduction}

The Sun is the original source of almost all energy available on Earth. There are several ways of controlled utilization of solar energy. Among many methods of photoconversion (conversion of solar radiation), one can distinguish photovoltaic and photothermal conversion. The fist one is a direct production of electric energy through the generation and separation of charges in the $\mathrm{p}$ $\mathrm{n}$ junction region of the semiconductor [1]. The second is used to convert solar radiation into heat.

The aim of the project was to create a system that combines those two types of photoconversion methods and applies them in one integrated device. Such solution would supply electric energy and support domestic water heating system, saving space (roof area), manufacturing materials and costs, which consequently reduces the production costs. However the concept of such solution is dated back to the last century and recently some practical applications have been proposed [2], there is no available in-depth analysis of the cross-dependence of thermal and opto-electrical parameters. This gave a prompt to a series of experiments leading to construction and laboratory tests of a few prototypes of the hybrid systems.

\section{Schematic idea of the project}

The idea of the project arose according to the effect of decreasing efficiency of PV modules under the influence of high temperatures. Standard conditions for solar cell operation are defined at the temperature of $25^{\circ} \mathrm{C}$ [3]. In practice, photovoltaic module under AM1.5 illumination in central Europe can be heated up to $80^{\circ} \mathrm{C}$, depending on mounting system and module technology. Operating temperature of a solar cell is determined by the ambient air temperature, by the intensity of sunlight falling on the module, and by other variables such as wind velocity and humidity. The effect of temperature on the maximum power output is dependent on thermal sensitivity of current and voltage. The short circuit current $\left(\mathrm{I}_{\mathrm{sc}}\right)$ increases slightly with temperature, since the effective bandgap energy $\left(E_{g}\right)$ decreases and more photons have enough energy to create charge pairs [4]. However, the main effect of increasing temperature on the cell output is a reduction in open circuit voltage $\left(\mathrm{V}_{\mathrm{oc}}\right)$ and fill factor (FF) [5]. The efficiency of such PV module drops in the range of $0.4 \%-0.9 \%$ (absolute) for each Celsius of increasing surface temperature.

In order to minimize this parasitic effect, authors proposed to transfer generated heat by applying copper pipes on the underside of PV module. Working medium that flows through channels, located beneath the surface, cools the photovoltaic module. Simultaneously, thermal energy, received by the medium, can be utilized for preheating water in the household. There are similar systems described by other authors, however neither experimental measurements of real construction performance nor practical applications ware noted. Practically, this type of hybrid device was not precisely investigated before. 


\section{Prototype $\mathbf{N}^{0} \mathbf{1}$, design and construction}

First system prototype was constructed following preliminary design shown in Fig. 1. The model device was designed for indoor/laboratory tests in undersized scale. The project design was created as two layered device. Front layer consists of nine single-crystalline silicon solar cells placed on electrically isolated copper plate. Bottom layer is copper coil pipe (Fig. 1).
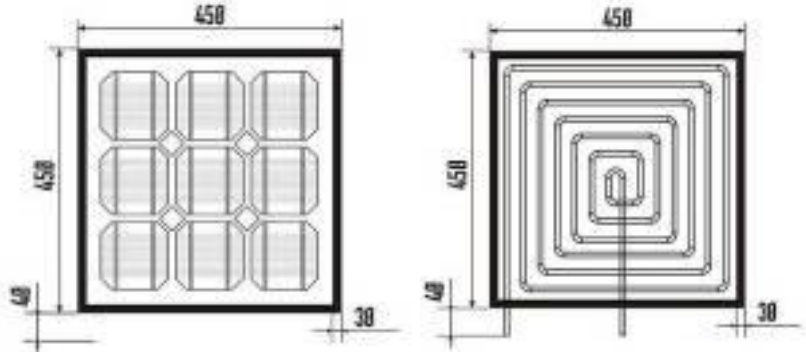

Fig. 1. Prototype $\mathrm{N}^{\mathrm{o}} 1$ system design: left - front (top) plate, right - back (bottom) plate.

Final construction was realized in accordance with the project above. Solar cells were connected in series-parallel way using metal tape and isolated from both sides with high temperature plastic spray. Top side was covered with thin and transparent plastic shield. Copper pipe was soldered to the bottom side of the plate. Fig. 2 illustrates the realization of described prototype. The whole system was integrated, thermally isolated and encapsulated simulate the real work conditions.
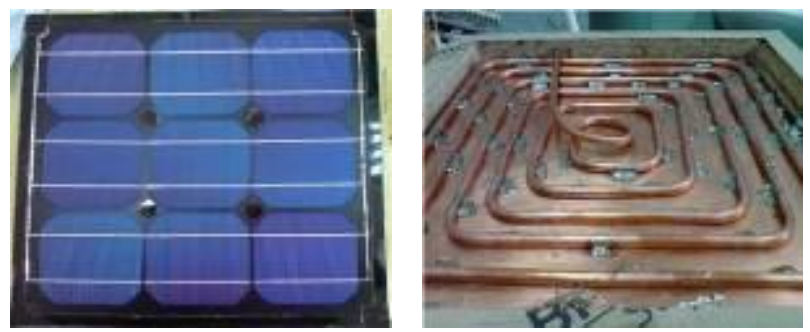

Fig. 2. The realization of the solar hybrid system first prototype: left - PV module, right - thermal collector.

To conduct research the installation must have been equipped with light source (solar simulator) and other peripheral apparatus (meters, regulated load, pump, heat receiving system). Fig. 3 presents the system of prototype $\mathrm{N}^{\mathrm{o}} 1$ under artificial illumination.

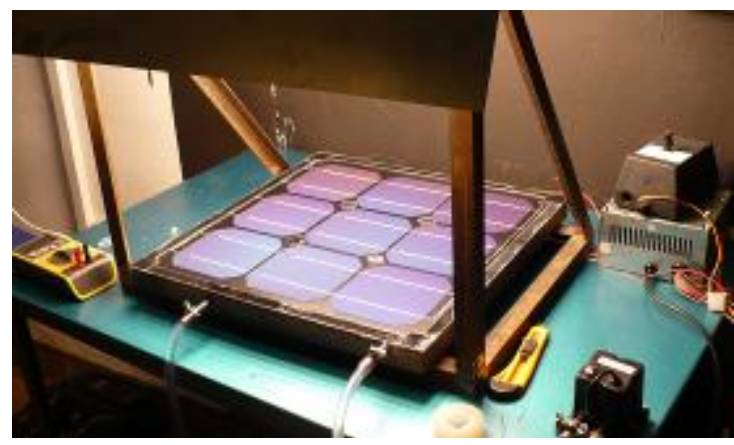

Fig. 3. Illuminated prototype $\mathrm{N}^{\mathrm{o}} 1$ model during tests.
Prototype number 1 is an original project, including several unique solutions, eg. spiral pipe for heat exchange, isolation and dimensions.

However, there is a demand to develop a device which would be suitable for relatively easy and cheap implementation, with no need of creating new lines of sophisticated and distinct processes, but using the existing and, as far as possible, local producers. This argument resulted in designing second prototype.

\section{Prototype $\mathrm{N}^{0} 2$, conception and realization}

General idea of the project is the same as in the first case and assumes insertion photovoltaic module directly at the thermal collector absorber's plate. The conception is precisely shown in Fig. 4.

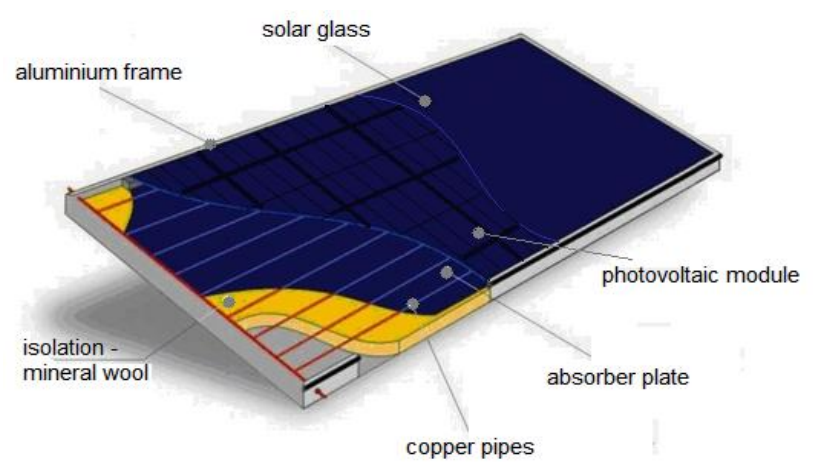

Fig. 4. The idea of the second prototype construction.

Second prototype, in contrast to the first one, was built using commercially available products, namely, factory made photovoltaic module and solar thermal collector. 50Wp PV panel - Solar Fabrik SP5 model and flat plate solar thermal collector, manufactured in local (Poland, Lodz) factory Ergom (Aparel), were used. Both devices were demounted and integrated in one hybrid system. Fig. 5 and 6 show the project realization steps.

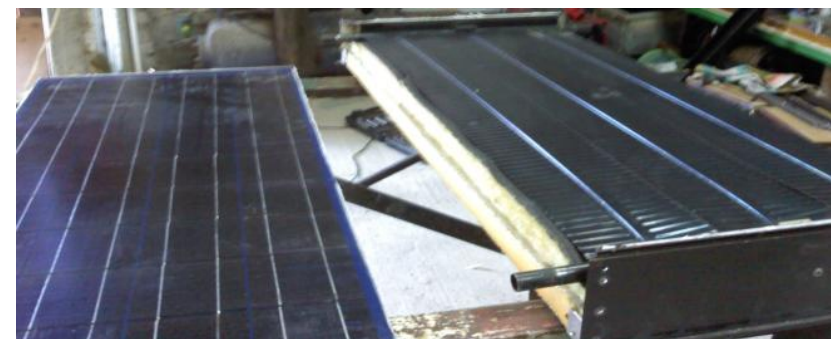

Fig. 5. Second prototype elements : PV module (left), solar thermal collector (right).

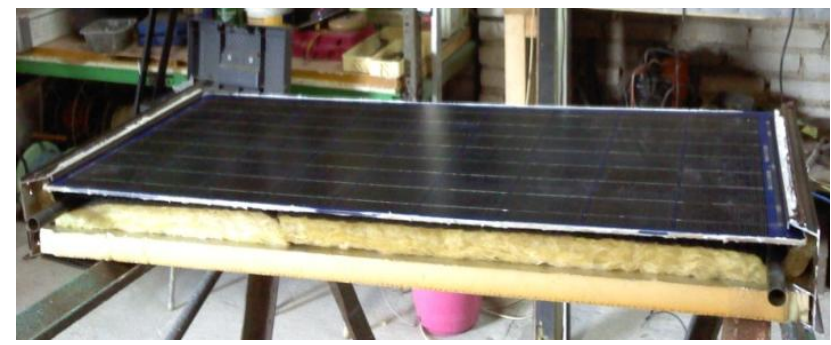

Fig. 6. Second prototype under construction. 
In this version PV module consists of 36 polycrystalline silicon solar cells connected in series and hermetically covered by solar glass. Thermal collector is made of three parallel copper pipes which are ultrasonically welded to copper plate and connected to two perpendicular bulk pipes. All this is both-side nickel-plated and coated with black chrome. Front glass, that covers collector, was removed and replaced with photovoltaic module. Because area dimensions of both devices was perfectly matched, this version of solar hybrid system seems to be very easy for implementation.

Because of autumn/winter season, there was no possibility to test this device in real atmospheric environment in central-east Europe conditions. In order to provide results of this work, there was a requirement to build solar simulator. Completed device is presented in Fig. 7

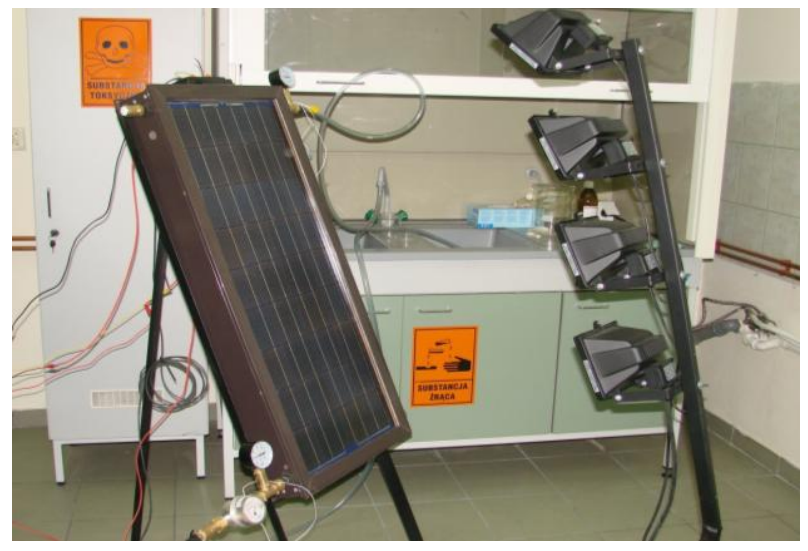

Fig. 7. Solar hybrid device - completed prototype $\mathrm{N}^{\mathrm{o}} 2$.

Indoor measurements was conducted to verify the functionality of constructed system and for comparison with the first prototype. Further tests are planned in real atmospheric conditions in the end of spring season.

\section{Measurement methods}

The most important parameters, to verify the theoretical assumptions, are output powers (electrical and thermal) and efficiencies. They were calculated using standard formulas for PV module (1) and thermal collector (2).

$$
\eta_{P V}=\frac{P_{\max }}{A_{t} \cdot E_{c}}
$$

$P_{\text {max }}$ - electrical power in maximum power point [W],

$A_{t}$ - surface area of the module $\left[\mathrm{m}^{2}\right]$,

$E_{c}$ - solar radiation that hits the surface $\left[\mathrm{W} / \mathrm{m}^{2}\right]$.

$$
\eta_{T}=\frac{Q_{e f f}}{Q_{a p p}}
$$

$Q_{\text {eff }}$ - collector effective thermal power [W],

$Q_{\text {app }}$ - collector applied power [W].

System temperature was monitored with the infrared camera VarioCAM ${ }^{\circledR}$ HiRes - Jenoptic of the following parameters: measurement accuracy $\pm 1.5 \mathrm{~K}$, spectral sensitivity 7.5-14 $\mu \mathrm{m}$, thermal resolution $<80 \mathrm{mK}$, image format $640 \mathrm{x} 480 \mathrm{px}$.
System parameters were measured in laboratory conditions under the illumination intensity of $360 \mathrm{~W} / \mathrm{m}^{2}$. This is almost three times lower value than the one recommended for STC (standard test conditions: $1 \mathrm{~kW} / \mathrm{m}^{2}$ ), however, at the preliminary investigation stage the major objective was rather to analyze the operation of integrated appliances or achieving the highest efficiencies.

\section{Results}

\section{A. First prototype}

As a first point of measurements, parameters of photovoltaic module without the support of solar collector were obtained. The results show that after about 20 minutes, device temperature raised up to $50^{\circ} \mathrm{C}$, which consequences in the drop of efficiency and maximum output power (Fig. 8). This is just the confirmation of the literature reports of high negative heat influence on PV module performance. In this case, deterioration of efficiency was about $0.75 \%$ (absolute) for one Celsius of temperature increase. This results corresponds with previous investigation performed for separated cells in laboratory STC conditions [6].

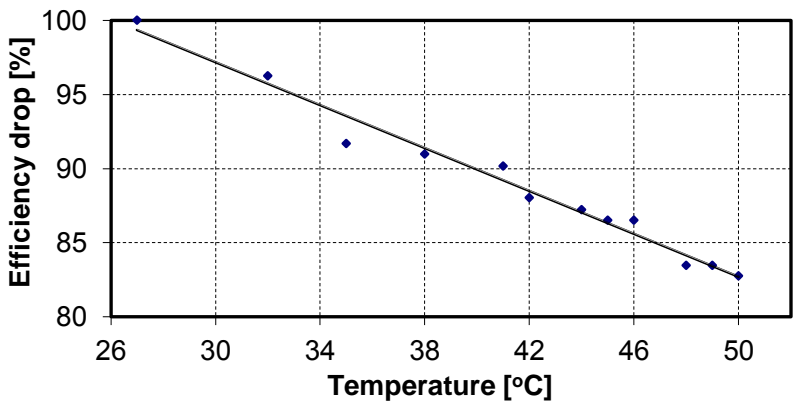

Fig. 8. Absolute decrease of PV module efficiency under the influence of increasing surface temperature (prototype $\mathrm{N}^{\mathrm{o}} 1$ ).

Second stage of the investigation was to find out how the system behaves while fluid flow in the copper coil pipe is on. Fig. 9 and 10 show thermographic pictures of the system surface, respectively: before and after turning on the flow of working medium.

The temperature of the surface raised up from $27^{\circ} \mathrm{C}$ to $50^{\circ} \mathrm{C}$ in about 20 minutes while cooling system was off. Ten minutes after fluid flux generation, surface temperature dropped to $36^{\circ} \mathrm{C}$, which causes module efficiency improvement.

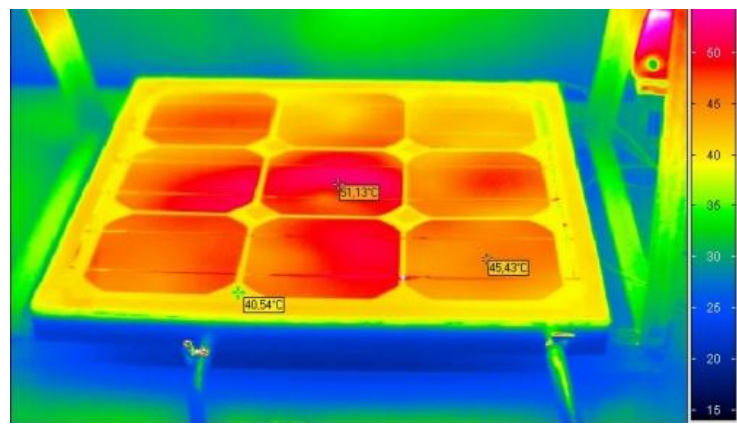

Fig. 9. Illuminated solar hybrid system working without liquid flow (solar thermal system is turned off). 


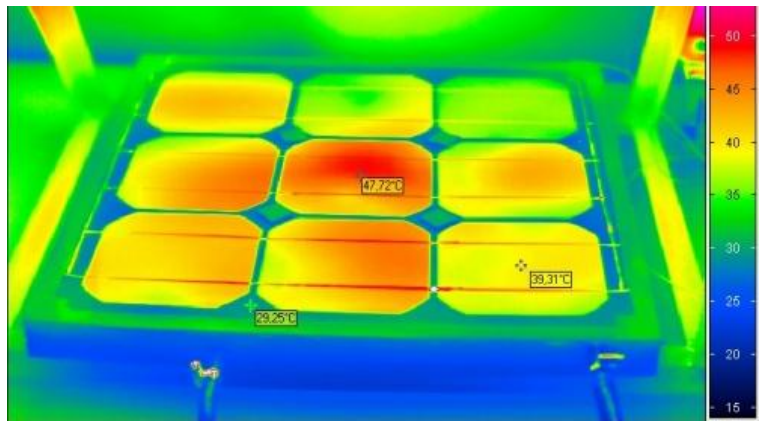

Fig. 10. Illuminated solar hybrid system 10 minutes after turning on the liquid flow.

The efficiency of solar thermal collector was calculated on the basis of applied power and received heat. The average was close to $70 \%$, which confirms the effect of system synergy and purposefulness of the project.

\section{B. Second prototype}

The parameters of second system were measured in analogue-approach as the first one. The results of first test step are shown in the Fig. 11. In this case, system, with flux fluid off, was exposed on the simulated irradiation during longer time period (above 0.5 hour). Module temperature reached $82^{\circ} \mathrm{C}$ and the deterioration of efficiency was about $0.52 \%$ (absolute) for one Celsius of temperature increase in relation to the nominal value. That also confirms literature range of efficiency decrease with high temperatures.

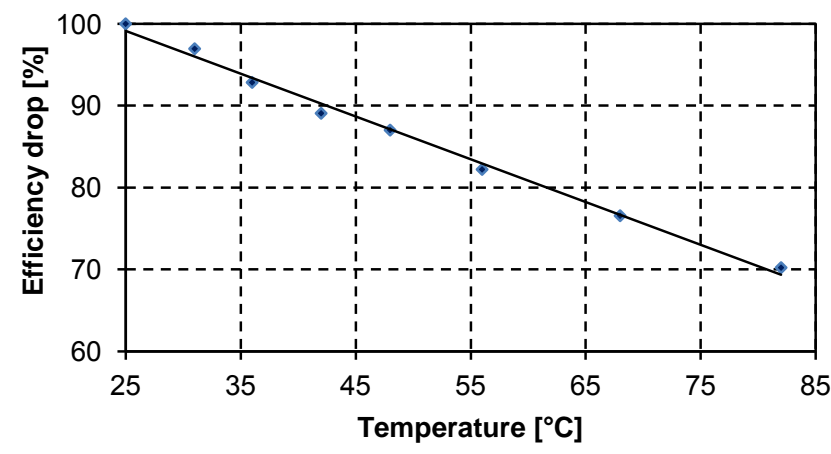

Fig. 11. Absolute decrease of PV module efficiency under the influence of increasing surface temperature (prototype $\mathrm{N}^{0} 2$ ).

The module temperature of the second prototype device started decreasing shortly after turning on solar thermal collector system located beneath photovoltaic surface. Final temperature stabilized at $42^{\circ} \mathrm{C}$. This phenomenon was analogous to that observed in first constructed device. Fig. 12 and 13 sow thermograms of surface temperature distribution respectively for heated system with no support of liquid flow in pipes and the same system with solar thermal collector turned on.

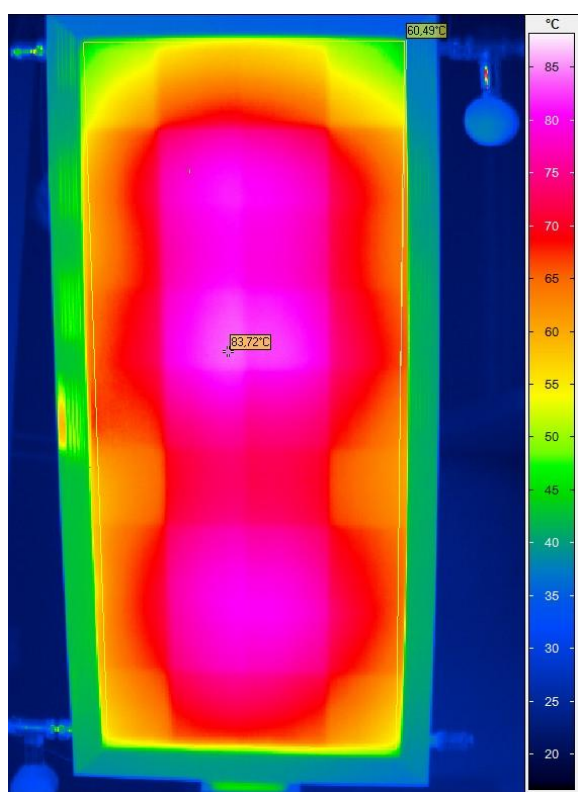

Fig. 12. Second version of solar hybrid system working without liquid flow (solar thermal system is turned off)

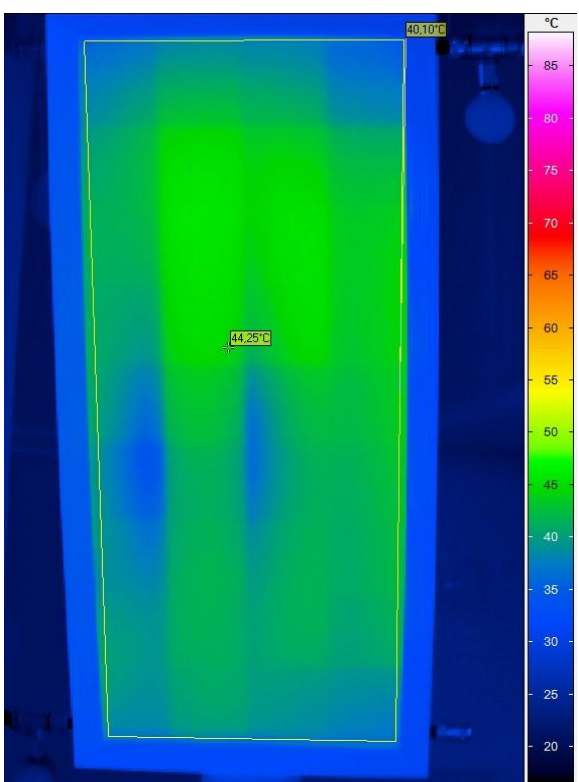

Fig. 13. Second version of solar hybrid system after 15 minutes of liquid flow (solar thermal system is turned on).

Cooling PV module from $82^{\circ} \mathrm{C}$ to $42^{\circ} \mathrm{C}$ enables to improve its efficiency from $70 \%$ to $90 \%$ of the standard test condition value. This is undeniable advantage of proposed solution. Moreover, there is also heat receiving from the system. In the second prototype, average thermal efficiency was calculated at the level of $65 \%$, which is satisfactory value.

\section{Conclusions}

Those two experiments showed that designed thermoelectrical hybrid system works properly, namely, efficiently cools photovoltaic plate and simultaneously heats flowing liquid that can be used for preheating water. Presented hybrid device for commercial implementation apparently requires further investigations and analysis. First of all measurements in standard test conditions 
according to solar radiation are needed and further research in real atmospheric environment. Next stage should include normalized mechanical, insulating and structural strength test. Finally optimum work configuration for new hybrid system should be elaborated.

However, after this preliminary analysis we can assume that this integrated thermo-electrical solar hybrid system is promising and future-oriented solution waiting for massscale implementation, however it's construction should be carefully optimized since it may strongly influence on work parameters.

\section{Acknowledgement}

Katarzyna Znajdek is a scholarship holder within the project entitled "Bioenergy for the Region - Integrated Programme for Ph.D. Students Development" supported by European Social Fund.

\section{References}

[1] K. Zweibel, P. Hersch, Basic Photovoltaic Principles and Methods, Van Nostrand Reinhold, New York (1984).
[2] S.B. Riffat and E. Cuce A review on hybrid photovoltaic/thermal collectors and systems 212 International Journal of Low-Carbon Technologies vol 6 No 3 September (2011).

[3] European Standard: IEC 60904-1 Photovoltaic devices Part 1: Measurement of PV current-voltage characteristics.

[4] O. Mah "Fundamentals of photovoltaic materials" National Solar Power Research Institute (1998).

[5] S. R. Wenham, M. A. Green, M. E. Watt, R. Corkish, Applied Photovoltaics, Earthscan, London and Washington, DC, (2007) pp. 47-49.

[5] T. Markvart, L. Castaner, Solar Cells: Materials, Manufacture and Operation, Elsevier, Oxford, (2005).

[6] K. Znajdek, M. Sibiński, Temperature coefficients comparison of thin film multicrystalline $\mathrm{Si}$ and flexible spherical Si solar cells-Laboratory researches. W: Photovoltaic Technical Conference - Thin Film 2010. Aix-en-Provence (2010). 